\title{
Povos indígenas isolados: autonomia e aplicação do direito de consulta
}

\author{
Isolated Indigenous people: \\ autonomy and aplication of consultations rights
}

Erika Magami Yamada ${ }^{1}$

Fabrício Ferreira Amorim ${ }^{2}$

\begin{abstract}
Resumo
O direito de auto-determinação dos povos indígenas - em harmonia com o conceito de Estados nações - é afirmado pela Declaração da Organização das Nações Unidas (ONU) sobre os Direitos dos Povos Indígenas, pela Declaração da Organização dos Estados americanos (OEA) e pela Convenção 169 da Organização Internacional do Trabalho (OIT). O direito de consulta livre, prévia e informada previsto na Convenção 169 da OIT constitui pedra angular do respeito à autonomia dos povos indígenas, garantindo-lhes a possibilidade de expressar consentimento ou não e influenciar tomadas de decisões governamentais que afetem suas vidas e seus territórios. Particularmente vulneráveis à violação de direitos humanos fundamentais, são os casos de medidas ou projetos estatais que afetam povos indígenas isolados. Nesses casos, exige-se um rol de ações estatais protetivas orientadas pela expressão de vontades desses povos. No Brasil, a metodologia de trabalho desenvolvida pela Funai tem permitido identificar e qualificar tais expressões de vontades para fazer avançar a proteção de direitos de povos indígenas isolados. A análise de três casos (Korubo e Piripkura no Brasil e Machiguenga-Nanti no Peru) à luz da prática indigenista, do Direito e da Antropologia, revela que decisões indígenas fundamentadas orientam diferentes estratégias de controle de relações (ou de isolamento) adotadas pelos povos isolados. Essas estratégias autônomas visam diminuir seu grau de vulnerabilidade e provocam tanto uma leitura diferenciada do direito de consulta previsto na Convenção 169 da OIT, quanto a construção de protocolos para o Estado reconhecer, respeitar e proteger os direitos e a vida dos povos indígenas isolados.
\end{abstract}

Palavras-chave: Povos Indígenas, Isolados, Consulta, Consentimento, Autonomia, Convenção 169/OIT.

\footnotetext{
Abstract

The rigth to self-determination of indigenous peoples - in harmony with the concept of nation states - is affirmed by the United Nations Declaration on the Rights of Indigenous Peoples, the Declaration of the Organization of American States (OAS) and the International Labor

${ }^{1}$ Relatora de Direitos Humanos e Povos Indígenas da Plataforma de Direitos Humanos (Dhesca), Brasil.

${ }^{2}$ Coordenador da Coordenação de Proteção e Localização de Índios Isolados (COPLII/ CGIIRC/Funai).
} 
Organization (ILO) Convention n.169. The right of free, prior and informed consultation provided in ILO Convention n.169 is the cornerstone of respect for the self-determination of indigenous peoples. It guarantees the possibility of indigenous peoples to express or not their consent towards and or to influence government decisions that affects their lives and territories. Particularly vulnerable to the violation of fundamental human rights are cases of state measures or projects that affect isolated indigenous peoples. In these cases, a series of protective state actions are deemed and should be defined considering the indigenous peoples and their expressions of wills. In Brazil, FUNAI's working methodology has allowed the identification and qualification of will expressions of isolated indigenous peoples to advance the recognition of their presence and the protection of their territorial rights. The analysis of three cases (Korubo and Piripkura in Brazil and MachiguengaNanti in Peru) considering indigenist practice, Law and Anthropology, reveals that isolated indigenous peoples make their decisions which guide different strategies of relationship control (or isolation) adopted by them. These autonomous indigenous strategies intend to reduce their degree of vulnerability. Therefore, they challenge us to consider particular specificities regarding the right to consultation provided in ILO Convention 169 and the State to establish special protocols to recognize, respect and protect the rights and lives of isolated indigenous peoples.

Key words: Isolated Indigenous people, Consultation, Consent, Autonomy, ILO Convention n. 169.

\section{Povos Indígenas Isolados}

A presença de povos indígenas isolados é conhecida em países da América do Sul: Bolívia, Brasil, Colômbia, Equador, Paraguai, Peru e Venezuela. Há indícios dessa presença também na Guiana (Francesa) e Suriname, regiões fronteiriças com o Brasil (CIDH 2013). Apesar de se tratar, em geral, de um "fenômeno" do bioma amazônico, é também conhecida a presença de grupos indígenas isolados no Cerrado brasileiro e na região do Gran Chaco, localizado entre o norte do Paraguai e sul da Bolívia.

O Brasil e o Peru são os países em que se registra a maior concentração de povos ou grupos indígenas isolados. No Brasil, estão registradas 103 regiões com presença de povos ou grupos isolados, desses registros, 26 estão confirmados (Amorim 2017). No Peru há pelo menos 16 registros de índios isolados (Huertas 2010), sendo que o Brasil e o Peru têm processos distintos de sistematização e reconhecimento da presença desses povos ou grupos isolados.

O Alto Comissariado das Nações Unidas para os Direitos Humanos (ACNUDH), após processo de consulta junto a países da América do Sul ${ }^{3}$ onde há a presença de índios isolados, publicou uma série de recomendações e definições que orientam o tema:

\footnotetext{
3 Bolívia, Brasil, Colômbia, Ecuador, Paraguai, Peru e Venezuela foram os países consultados.
} 
Los pueblos en aislamiento son pueblos o segmentos de pueblos indígenas que no mantienen contactos regulares con la población mayoritaria, y que además suelen rehuir todo tipo de contacto con personas ajenas a su grupo. También pueden ser grupos pertenecientes a diversos pueblos ya contactados que tras una relación intermitente con las sociedades envolventes deciden volver a una situación de aislamiento como estrategia de supervivencia y rompen voluntariamente todas las relaciones que pudieran tener con dichas sociedades. (...) (ACNUDH 2012).

O uso do termo "isolados" neste artigo engloba casos de pequenos grupos indígenas "isolados", muitas vezes segmentos de povos que já estabelecem contatos sistemáticos, que rechaçam a todo custo qualquer relação com outros agentes, bem como povos "isolados" de tamanho considerável que estabelecem certo grau de relações com seu entorno e complexas redes de trocas e relações entre si. Nesse sentido, é consenso que o conceito "isolado" não representa plenamente as complexas e distintas estratégias desenvolvidas pelos povos ou grupos assim classificados. Entretanto, não há um consenso sobre qual(is) seria(m) o(s) termo(s) mais adequado(s), de modo que o termo "isolados" segue sendo comumente utilizado, inclusive pelas políticas públicas no Brasil e no Peru.

A discussão sobre o uso do termo isolado engloba questões relativas à impossibilidade de existir sociedades humanas que nunca estabeleceram relações com outra. Daí, a reflexão aponta a necessidade de se agregar à discussão, parâmetros que relativizem o isolamento frente ao outro. (Vaz 2012)

A discussão acerca do termo "isolados" pode ser considerada uma tradução por comparação visto que se refere a uma série de contextos ou situações sociais diferenciadas de povos indígenas. Sendo uma "tradução", existe uma presunção de diferenças ou equívocos inerentes à nossa relação e à relação de Estado com as sociedades indígenas (Viveiros de Castro 2004), fundadas também num Direito colonizador. Ou seja, ao definirmos e utilizarmos essa identidade ou categoria de identidade de "isolados" como uma ferramenta analítica, simplificamos mundos a partir do nosso entendimento de práticas e conceitos.

No entanto, mesmo diante dessas limitações, a possibilidade de refletir sobre povos indígenas "isolados" tem permitido inovar conceitos, inclusive jurídicos, e compreender cosmologias sobre os quais temos poucas referências cartesianas de conhecimento. No caso dos "isolados" é evidente que a maior parte das, senão todas, comparações e conceituações são feitas a partir daquilo que nos é "deixado" pelos indígenas, somado ao que nos define enquanto sociedades externas devastadoras. Por exemplo, aponta o Relatório da Comissão Inter- 
Americana de Direitos Humanos da Organização dos Estados Americanos (CIDH):

18. Como punto de partida, la CIDH entiende que el marco jurídico del Derecho internacional de los derechos humanos, desarrollado por las sociedades occidentales contemporáneas, responde a conceptos que los pueblos indígenas en aislamiento ciertamente desconocen. No obstante, este marco de respeto a la vida, a la integridad y a las libertades fundamentales de todos los seres humanos es la mejor herramienta para proteger la manera en que estos pueblos expresan su humanidad.

19. La Comisión considera que, en el análisis de la situación de derechos humanos de los pueblos indígenas en aislamiento voluntario y contacto inicial, es fundamental tener presente lo devastador que puede resultar para ellos la destrucción de un plantio, la contaminación de un río, la deforestación de un bosque, $\mathrm{y}$ otras afectaciones al entorno en el que habitan y del que dependen. (CIDH 2013)

Utilizando essa mesma ferramenta analítica de tradução de conceitos para expressar reflexões extraídas de atividades em campo, podemos afirmar que as relações estabelecidas pelos diferentes grupos ou povos isolados ocorrem sob diferentes formas e gradações de intensidade. No entanto, em todos os casos, há uma manifestação clara dos povos ou grupos indígenas isolados de não aceitação de relações intensas ou constantes com seu entorno. Isso pode ser traduzido comparativamente pela afirmação externa de que estes povos não estão dispostos a relações forçadas nem a formas de interação que não desejam.

Neste artigo, abordamos algumas situações específicas dos povos Korubo e Piripkura no Brasil, e do povo Machiguenga-Nanti no Peru. Esses povos expressam diferentes estratégias de relação com o que chamamos ou traduzimos como "entorno" e exigem ações estatais, ou políticas que protejam seus espaços vitais, inclusive de pressões por parte de empresas e outros invasores. Os casos abordados oferecem elementos importantes para a discussão e melhor tradução do "direito de consulta" para fazer respeitar as estratégias de vida desenvolvidas por povos grupos isolados, especialmente no contexto de interesses de exploração econômica dos recursos naturais em seus territórios e entorno. O Relatório da Comissão Interamericana de Direitos Humanos afirma nesse sentido:

Las distintas amenazas que atentan contra los derechos de los pueblos en aislamiento y contacto inicial tienen como causa común el contacto, ya sea directo o indirecto, con personas ajenas a sus pueblos. Las agresiones físicas directas, las incursiones a sus territorios con el objetivo de extraer recursos naturales, las epidemias, la escasez de 
alimentos, y la pérdida de su cultura, todas presuponen un contacto. Si se elimina el contacto no deseado, se eliminan la mayoría de las amenazas y se garantiza el respeto a los derechos de tales pueblos. Por lo tanto, en opinión de la Comisión, es fundamental que todo esfuerzo por afianzar este respeto se rija fundamentalmente por el principio de no contacto, y de que el contacto se debe dar solamente si es propiciado por los pueblos en aislamiento. (CIDH 2013)

\section{Políticas Públicas e Marcos Legais}

No Brasil, a atual política de proteção e promoção dos direitos de povos indígenas isolados surge a partir de $1987^{4}$, e se relaciona com o processo da Constituinte de 1988. Antes disso, acreditava-se que a única forma de proteger esses povos e garantir seus direitos era através do contato. A Constituição Federal de 1988 reconheceu em seus artigos 231 e 232, os modos de vidas diferenciados dos povos indígenas, desconstruindo os conceitos de integração e tutela. Essa mudança de paradigma geral de proteção dos direitos indígenas também se manifestou mundialmente no contexto de revisão da Convenção 107 da Organização Internacional do Trabalho $(\mathrm{OIT})^{5}$. As discussões para revisão desse tratado internacional ocorreram a partir de 1985, resultando, no ano de 1989, na Convenção n. 169 da OIT que é hoje o principal instrumento vinculante de defesa de direitos dos povos indígenas no mundo.

Dentre os países sulamericanos, o Brasil foi o primeiro a reconhecer oficialmente, o "direito" dos povos indígenas isolados a exercerem suas estratégias de isolamento, considerando-as como expressão de sua autodeterminação. ${ }^{6}$ Destacou-se desde então na política pública brasileira a expertise para a implementação e execução de ações em campo que materializam os preceitos legais de proteção dessa condição de isolamento voluntário.

A metodologia ${ }^{7}$ desenvolvida e aprimorada nos anos posteriores a 1987, tornou possível o dimensionamento territorial e a identificação sociocultural dos grupos ou povos indígenas isolados, sem se estabelecer contatos forçados. Essa metodologia, em contínuo desenvolvimento, hoje considera como etapas

${ }^{4}$ Criação do Sistema de Proteção aos Índios Isolados (SPII), pelas Portarias da Funai n. 1900 e 1901, ambas de 1987.

${ }^{5}$ A Convenção n. 107 foi adotada em 1957. Na época ,os povos indígenas e tribais eram considerados sociedades atrasadas e transitórias. Para que pudessem sobreviver, se acreditava indispensável fundi-las à comunhão nacional, mediante a integração e assimilação.

${ }^{6}$ Entretanto, só em 2004, o Brasil ratificou a convenção n 169 da OIT.

${ }^{7}$ Destaca-se a metodologia desenvolvida pela Equipe de Localização Guaporé, da Funai. A metodologia desenvolvida por essa equipe permitiu, pela primeira vez na história, a regularização fundiária de uma Terra Indígena (TI) de usufruto exclusivo de um povo isolado (TI Massaco, em Rondônia), sem que nenhum contato fosse estabelecido. 
de trabalhos: a) pesquisa/qualificação bibliográfica/documental; b) coleta e sistematização de relatos de terceiros; c) análise de dados cartográficos e geoprocessamento, d) sobrevoos, e e) expedições em campo. Geralmente, a etapa da expedição em campo é o desdobramento final de um processo anterior de planejamento e qualificação de informações sobre a presença de isolados em determinada região. Essas etapas anteriores direcionam as estratégias do processo de expedição em campo.

A expedição em campo permite a identificação e o registro (documental e audiovisual) de vestígios de grupos isolados, comprovando sua presença e de dados sobre os processos de uso e ocupação indígena do território. Com essa metodologia é possível identificar algumas estratégias de organização social desses grupos em seus territórios, como por exemplo com relação aos recursos naturais que utilizam considerando a distribuição desses recursos em seus espaços. Tais dados e informações fundamentam ações de proteção e regularização fundiária como o resguardo, por parte do Estado, dos espaços, das relações e dos recursos ambientais imprescindíveis aos processos de vida desses povos. Além disso, através dessa metodologia, é também possível levantar dados sócio-culturais e demográficos sobre esses grupos.

Nos outros países, o desenvolvimento de uma política pública de proteção - considerando o respeito ao isolamento - é relativamente recente, não obstante vem avançando, como no caso da Colômbia ${ }^{8}$. Bolívia e o Equador são os únicos países com garantias constitucionais específicas relacionadas aos direitos dos povos indígenas isolados. A Bolívia, no entanto, não dispõe de práticas sistemáticas em campo. No Peru, apesar de existir uma estrutura normativa diferenciada, são reportadas dificuldades na implementação de práticas em campo, que resultem na efetivação da política pública a contento.

No âmbito internacional, a convenção ${ }^{\circ} 169$ da OIT é um dos principais instrumentos legais que alicerçam as políticas regionais de proteção aos povos indígenas isolados juntamente com a Declaração sobre os Direitos dos Povos Indígenas ${ }^{9}$, as diretrizes do Alto Comissariado das Nações Unidas para os Direitos Humanos (ACNUDH) e as recomendações constantes do Relatório da Comissão Inter-Americana de Direitos Humanos (CIDH, 2013). Em 2016

\footnotetext{
${ }^{8}$ A título de exemplo, destacamos o desenvolvimento de ferramentas de localização e monitoramento por sensoriamento remoto, e construção de planos de contingência em caso de contatos.

${ }^{9}$ No dia 13 de setembro de 2007, a Assembleia Geral da ONU adotou a Declaração sobre os Direitos dos Povos Indígenas, marcando o fim de anos de estudos e trabalhos conjuntos entre governos, povos indígenas e especialistas de todo o mundo. Com a adoção da Declaração, a mais importante instituição de sociedade organizada do mundo - as Nações Unidas proclamou o que deveria ter sido afirmado há muito tempo, mas não era amplamente aceito: que os povos e indivíduos indígenas, suas culturas e modos de vida, estão à altura de todos os outros em dignidade e valor.
} 
foi aprovada no âmbito da Organização dos Estados Americanos a Declaração sobre os Direitos dos Povos Indígenas que conta com um artigo específico para tratar do compromisso dos Estados com os direitos isolados.

\section{Convenção 169 da OIT}

A Convenção n 169 da Organização Internacional do Trabalho (OIT)/1989 versa sobre direitos de povos indígenas e tribais (quilombolas e povos tradicionais) num contexto de reconhecimento da diversidade sociocultural dos países signatários (Rojas Garzón 2016) e de reflexão crítica acerca de processos de colonização de povos independentes. Assim, tem como pedra angular o reconhecimento do direito à autonomia ou autodeterminação dos povos indígenas, cujos conceitos se aprimoraram ao longo dos anos para compatibilizar a o entendimento da autonomia indígena sobre suas vidas, suas formas de organização e na gestão de suas terras dentro da estrutura de Estado Nacional.

Aprovada em 2007, a Declaração da ONU sobre Direitos dos Povos Indígenas reconhece a necessidade de proteção dos direitos de autodeterminação, de consulta e de consentimento dos povos indígenas. Esse entendimento tem sido reafirmado na interpretação e aplicação dos demais instrumentos internacionais de direitos humanos pela jurisprudência nacional e internacional de direitos humanos. (Garzón, Yamada e Oliveira 2016)A Comissão e a Corte InterAmericana de Direitos Humanos já afirmaram em diversos casos julgados ${ }^{10} \mathrm{e}$ pronunciamentos que os povos indígenas tem direito à sua identidade cultural, e que os Estados devem garantir o direito dos povos indígenas de viverem em seus territórios ancestrais para preservar tal identidade.

Bolívia, Brasil, Colômbia, Equador, Paraguai e Peru ratificaram a Convenção 169 da OIT. No Brasil, a Convenção 169 foi ratificada em 2002, e incorporada ao ordenamento jurídico nacional através do Decreto ${ }^{\circ} 5051 / 2004$. Os direitos previstos na Convenção são auto-aplicáveis no Brasil e se elevam à categoria de direitos fundamentais. $\mathrm{O}$ direito de consulta, previsto nos artigos $6^{\circ}$ e $15^{\circ}$ da Convenção 169 da OIT harmoniza-se com os direitos salvaguardados nos artigos 231 e 232 da Constituição Federal que reconhecem aos povos indígenas o direito de viverem segundo suas formas próprias de organização social, usos, costumes e tradições, salvaguardam as terras tradicionalmente ocupadas pelos povos indígenas e estabelecem a necessidade de oitiva às comunidades indígenas no caso de exploração de recursos hídricos e minerais em terras indígenas, dentre outros.

Nesse mesmo sentido, os artigos 4o e 7o da Convenção 169 da OIT encontram

${ }^{10} \mathrm{CIDH}$. Derechos de los pueblos indígenas y tribales sobre sus tierras ancestrales y recursos naturales. Normas y jurisprudencia del sistema Interamericano de derechos humanos. OEA/Ser.L/V/II, 30 de diciembre de 2009. 
amparo constitucional à medida que salvaguardam respectivamente as pessoas, instituições, os bens, as culturas e o meio ambiente dos povos indígenas, bem como o direito de definição de suas próprias prioridades de desenvolvimento e de participação nas definições de planejamentos e tomadas de decisões que os afetem. A jurisprudência nacional e internacional confere parâmetros ao entendimento de que essa afetação deve ter enfoque em direitos substantivos. Ou seja, determinada medida deverá ser consultada, sempre que impactar sobre direitos estabelecidos e reconhecidos dos povos indígenas.

\section{Direito de consulta}

Chave para o reconhecimento da autonomia dos povos indígenas, o direito de consulta livre, prévia e informada é considerado como um princípio geral de Direito Internacional. ${ }^{11}$ Ainda que a falta de sua implementação seja constantemente denunciada pelos povos indígenas ${ }^{12}$, a realização de consulta livre, prévia e informada e a observância do consentimento indígena é um direito legalmente exigível sempre que uma medida administrativa ou legislativa afetar direitos dos povos indígenas. ${ }^{13}$

O dever de consultar os povos indígenas aplica-se sempre que uma decisão do Estado possa afetar os povos indígenas em maneiras que não são percebidas pela sociedade em geral (ANAYA 2013). Isso porque, a consulta e participação nos termos previstos pela Convenção 169 da OIT auxiliam os Estados a efetivamente respeitar os povos indígenas na sua diversidade, inclusive a partir de sua visão de organização e desenvolvimento. Esse tratado internacional exige que os Estados conheçam e considerem os pontos de vistas, os valores, os entendimentos e as regras dos diferentes povos indígenas, sobre diferentes assuntos. Para tanto, um processo de consulta deve ocorrer antes da tomada de decisões que possam afetar estes povos indígenas (Garzón, Yamada e Oliveira 2016), inclusive no caso de "isolados".

A consulta é um processo que prevê um diálogo, ou uma interação, de boa-fé do Estado com os povos indígenas afetados e, portanto, deve ser adequadamente informado, livre de pressões e respeitoso com os povos indígenas. A consulta deve envolver um processo que entenda e considere os posicionamentos e interesses relativos às especificidades dos povos indígenas, a fim de aprimorar a tomada de decisão pelo Estado (Yamada \& Oliveira 2013). Por isso, os Estados

\footnotetext{
${ }^{11} \mathrm{O}$ direito de consulta livre, prévia e informada é considerado como um princípio geral de Direito Internacional (Sarayaku v. Equador)

${ }^{12}$ Ver as informações da Rede de Cooperação Amazônica sobre a violação do direito de consulta pelo Estado Brasileiro encaminhada para a Relatora da ONU sobre os Direitos dos Povos Indígenas: http://rca.org.br/wp-content/uploads/2016/08/iepé-RCA-consultaportuguês.pdf

${ }^{13}$ Art.6 Convenção 169 da OIT.
} 
precisam desenvolver mecanismos apropriados de informação, diálogo, escuta e garantia de influência dos povos indígenas nas decisões de governo (Yamada 2013). Ainda nos termos da Convenção n ${ }^{\circ} 169$ da OIT, cabe aos Estados garantir condições para que as consultas sejam realizadas, sempre respeitando as formas de organização e representatividade dos povos indígenas. Fundamentalmente, o direito de consulta propõe um novo modelo de relação do Estado com povos indígenas, fundado no respeito aos direitos humanos e à autonomia dos povos indígenas.

\section{Consentimento e autonomia}

Indissociável do direito de consulta está o direito dos povos indígenas de definirem seus processos de desenvolvimento ou planos de vida de acordo com suas livres vontades, seu bem-estar espiritual, suas instituições e crenças, ou seja, o direito ao reconhecimento de sua autonomia. ${ }^{14}$ Assim, em alguns casos, além dos direitos de participação e de consulta aos povos indígenas, é exigível que o Estado obtenha o consentimento dos povos indígenas para que determinadas atividades ou projetos se desenvolvam em suas terras. ${ }^{15}$ Tratam-se de casos em que a autonomia ou autodeterminação de um determinado povo ou grupo indígena está sob risco.

Tal medida visa garantir que não se imponham situações de violação de direitos fundamentais e evitar a desproporcionalidade da medida a ser adotada pelo Estado frente aos impactos sobre direitos indígenas específicos (ANAYA 2013). Essa exigência garante coerência entre a observância do direito de consulta, a garantia dos direitos substanciais e o respeito à autonomia ou autodeterminação dos povos indígenas. Nesse sentido, situações em que os povos indígenas se recusam a ser consultados também devem ser consideradas pelo Estado nos processos de tomada de decisão. Trata-se, em geral, da manifestação do não-consentimento dos povos indígenas afetados e, muitas vezes, revelam a desproporcionalidade da magnitude dos impactos sobre direitos indígenas (ANAYA 2013).

Além do dever de consultar, os Estados têm deveres nacionais e compromissos

\footnotetext{
${ }^{14}$ Art. 7 Convenção 169 da OIT.

${ }^{15}$ Para la Corte Interamericana de Direitos Humanos la participación efectiva del pueblo en la toma de la decisión del poder público que puede llegar a amenazar sus posibilidades de continuar su vida como pueblo, solo puede constituirse en garantía efectiva de que eso no suceda, en la medida de que el consentimiento del pueblo consultado sea determinante para la adopción o no de la decisión consultada. Por tanto la Corte ha resuelto que cuando se trate de planes de desarrollo o de inversión a gran escala que tendrían un mayor impacto dentro del território Saramaka, el Estado tiene la obligación, no sólo de consultar a los Saramakas, sinotambién debe obtener el consentimiento libre, informado y previo de éstos, según sus costumbres y tradiciones. ANAYA 2013 Corte Interamericana. Sentencia caso Saramaka $v$. Suriname. 28 de noviembre de 2007
} 
internacionais, inclusive inscrito na Convenção 169 da OIT e nas Declarações da ONU e da OEA, para respeitar e proteger direitos fundamentais dos povos indígenas, como o direito à vida, às terras e recursos naturais que garantam condições para a integridade física e social do grupo, e o direito de não serem removidos de suas terras tradicionalmente ocupadas (art.231 CF/88).

\section{E em caso de isolados?}

Considerando que os grupos ou povos indígenas isolados não estabelecem relações contínuas e constantes com a sociedade nacional, e as diretrizes nacionais e internacionais de não imposição do contato, como ocorreria o processo de consulta do Estado junto a esses povos? Seria o caso de uma exceção a esse direito?

Medidas ou projetos que afetam regiões ou terras indígenas com presença de povos ou grupos indígenas isolados merecem especial atenção no que tange aos processos de consulta livre, prévia e informada nos termos da Convenção ${ }^{\circ}$ 169 da OIT. As especificidades destes povos ou grupos apontam que o próprio contato forçado coloca em risco a vida e a autonomia desses povos. Portanto, não seria possível a imposição, por parte do Estado, de um processo de consulta "padrão", ou que não respeite essa maior especificidade dos isolados. Exatamente por estarem particularmente vulneráveis a situações extremas de violação de direitos humanos fundamentais - incluindo-se o risco de genocídio - é necessário que o Estado observe com cautela ainda maior os modos e estratégias de vida destes povos antes da tomada de qualquer decisão que os possam afetar. Fundamentalmente, é necessário que ao reconhecer e garantir a autonomia de povos e grupos "isolados" também se permita a influência destes povos nas tomadas de decisões estatais que os afetem. Isso deve se dar por meio da compreensão sobre suas formas de expressão e de vidas diferenciadas.

Assim, não se trata necessariamente de exceção ao direito de consulta, mas de sua releitura para considerar os limites da relação desses povos com o Estado e a sociedade envolvente. Essa releitura do direito de consulta não pode privar povos indígenas isolados do gozo de direitos fundamentais. À luz do escopo maior da Convenção 169 da OIT - reafirmado pelas Declarações da ONU e da OEA sobre os Direitos dos Povos Indígenas - e conforme a Constituição Federal brasileira de 1988, o Estado deve estabelecer relações respeitosas aos modos de vida diferenciados dos povos indígenas. ${ }^{16}$

No caso dos povos ou grupos indígenas isolados, a releitura do direito de consulta não deve implicar contradição com o respeito à estratégia de isolamento

\footnotetext{
${ }^{16}$ A Declaração da ONU sobre os direitos dos povos indígenas aprovada pela Assembléia Geral da ONU em 2007 estabelece que os povos indígenas têm direito à autodeterminação e, no exercício de tal têm, o direito à autonomia ou autogoverno das questões relacionadas a seus assuntos internos.
} 
destes povos. Afinal, o que se busca com o direito de consulta livre, prévia e informada não são meras reuniões, distribuição de materiais informativos, conversas e atas. Busca-se, acima de tudo, o reconhecimento da presença indígena em áreas afetadas por medidas governamentais e o efetivo respeito por parte do Estado aos modos e planos de vidas, às culturas e cosmologias indígenas sobre os quais, em geral, pouco se sabe.

\section{A expressão da autonomia e das vontades de povos indígenas isolados}

Para os povos indígenas, inclusive os isolados, assim como para as sociedades não-indígenas, as relações e trocas sociais que se estabelecem ao longo de suas histórias são formadoras de identidades e fundamentam visões de mundo.

Os termos "relações" e "trocas" são utilizados aqui para se referir não são apenas a experiências com contatos físicos, constantes e/ou intensos mas para traduzir relações, de diferentes molduras, que operam em qualquer conjuntura social.

"Contato" entre grupos humanos pressupõe, sempre, alguma troca, seja de informações, de bens, de mulheres e homens ou de símbolos. Há uma gradação e diversas modalidades de troca (a guerra é uma delas), de forma que se pode classificar as sociedades como mais abertas ou mais fechadas a trocas (gradação), porém estes graus de abertura dependem das estratégias intencionais das sociedades. (Octavio \& Azanha 2009)

Observa-se, por exemplo, que muitos povos ou grupos isolados dominam a técnica do uso de instrumentos de corte metálicos (machado e terçado) para a derrubada de roçados, dentre outros usos. A apropriação dessa tecnologia não é recente e demonstra que existiram (e existem) momentos de "relações" que propiciaram e propiciam a obtenção dessas ferramentas e a apropriação do uso dessa tecnologia pelos chamados "saques furtivos". Contudo, apesar do desejo ao acesso dessas ferramentas, esses povos parecem rechaçar qualquer tentativa de contato físico e direto com a nossa sociedade. Tal postura ajuda a traduzir suas expressões de autonomia e tomada de decisões.

Podemos afirmar que existe uma diversidade de formas e de gradações que nos ajudam a traduzir muitos tipos de relações que os isolados estabelecem com relação à nossa sociedade, e que denominamos de estratégias de "isolamento". Há casos em que esses grupos ou povos evitam constantemente qualquer tipo de contato, sendo o controle das relações por eles mais rígido. Há outros casos em que a intensidade varia conforme os contextos e os agentes de interlocução. 
Para muchos pueblos o fragmentos de ellos el aislamiento fue una estrategia de sobrevivência escogida y decidida a consecuencia de la relación que mantienen con su entorno y con actores de los cuales no se encuentran desvinculados por completo. Sus contactos con los representantes de la sociedad nacional se mantienen todavia mediante rápidos avistamientos, en algunos casos violentos y conflictivos ("robo" de objetos de casas próximas) o se manifiestan en una evitación completa. (Nascimento 2011)

De fato, o próprio rechaço de relações pode ser traduzido ou entendido como um tipo de "reação" e pressupõe alguma forma de relação com o outro:

En efecto, como se ha visto, en algunos casos se trata de pueblos, en la mayoría, de segmentos remanentes de éstos que como consecuencia de procesos regionales han asumido el aislamiento como tipo de relación con el entorno. (Huertas 2010)

Portanto, o que ocorre, não é simplesmente uma decisão de não relação, mas estratégias conscientes, que se originam a partir de relações com o outro, cujo objetivo é exatamente ter maior seletividade, controle ou gestão dessas interações sociais, físicas ou até espirituais. Nesses casos, os "isolados" nos transmitem mensagens, que podemos traduzir ou compreender - dentro das limitações colocadas pelos nossos próprios códigos - como manifestações de autonomia no que diz respeito a seus direitos territoriais e sobre os recursos naturais de que prescindem. Conclui-se, assim, e a partir de observação de casos concretos, que as estratégias de "isolamento" são melhor traduzidas como estratégias de relação, do que como de não relação.

O outro está sempre presente nas ações dos povos indígenas amazônicos, e pode-se argumentar que é onde essas ações se originam (Viveiros de Castro 2002, in Gow 2011).

E conforme observado no caso dos Ava Canoeiro no alto rio Tocantins, quando ainda "isolados", adotavam estratégias pautadas por relativa gestão da distância, em contraposição às iniciativas de atração de equipes da Funai nas décadas de 70 e 80 :

Se considerarmos que o contato se pautava pelo desconhecimento mútuo quanto às formas de etiqueta e comunicação com pessoas estranhas ou inimigas, podemos dizer, então, que os avá-canoeiros optaram por uma relação ou troca silenciosa com sertanistas e regionais como forma de envolvê-los em uma relação harmoniosa." (Silva 2006) 
Povos ou grupos indígenas isolados têm formas diferenciadas de vida, sendo necessário correlacioná-las às nossas em um mesmo nível de contemporaneidade para que de fato os direitos fundamentais previstos nas legislações nacionais e internacionais sejam resguardados. Grupos ou povos isolados, em geral, possuem um grau de conhecimento sobre seu entorno que arriscamos afirmar ser maior do que o grau de entendimento que temos - enquanto entorno não indígena, sociedade majoritária ou externa - sobre eles.

Por isso, é possível afirmar que as estratégias de relações que eles desenvolvem com relação a nós tendem a ser mais exequíveis do que as estratégias que adotamos com relação a eles. Para que nossas estratégias, especialmente as estatais - e inclusive as jurídicas - garantam efetivamente sua proteção, estas devem ser construídas considerando de fato elementos de seus processos decisórios.

\section{As diferentes expressões de autonomia dos povos isolados: o caso do povo Korubo no Brasil}

O povo Korubo fala uma língua da família Pano (Oliveira 2009) e, no Brasil, habita regiões inseridas pela Terra Indígena Vale do Javari, no estado do Amazonas. Atualmente, estão divididos em cinco grupos, dois em situação de isolamento e três em situação de recente contato. A população de recente contato é constituída por 83 pessoas, enquanto a população que permanece em situação de isolamento é similar ou ligeiramente inferior a esta em termos demográficos. ${ }^{17}$ Os grupos recém contatados — outra categoria de tradução e simplificação comparada - iniciaram relações mais intensas com o entorno em épocas diferentes entre si.

O primeiro grupo estabeleceu contato em 1996, com a Funai, o segundo em 2014 e o terceiro em 2015, com indígenas Kanamary e Matis respectivamente. A atual distribuição do povo Korubo é possivelmente resultado de uma diáspora fruto de sucessivos processos migratórios que ocorreram em consequência da pressão devastadora da exploração econômica de seus territórios entre as décadas de 1970 e 1990. Destacam-se a prospecção de hidrocarbonetos, ocorrida na década de 1980 e a exploração madeireira, entre as décadas de 1970 até finais da década de 1990. (Coutinho 1998 ; Labiak 1984)

O povo Korubo é aquele com o qual houve o maior número de conflitos registrados com frentes econômicas na região do Vale do Javari - madeireiros, seringueiros e equipes de prospecção de hidrocarbonetos. A Fundação Nacional do Î́ndio (FUNAI), nas décadas de 70 e 80, desencadeou inúmeras tentativas de contatá-los, todas frustradas, havendo inclusive a morte de funcionários durante

${ }^{17} \mathrm{O}$ número varia entre quatro a três a quatro malocas, conforme suas dinâmicas próprias de ocupação. (Relatórios de sobrevoo de Fabrício Amorim/Funai , 2010, 2011, 2012, 2013) 
as tentativas de atração. ${ }^{18}$ As tentativas de contato ocorridas na década de 1970 se deram no contexto da construção de um trecho da estrada "perimetral norte", que ligaria os municípios de Benjamim Constant/AM e Cruzeiro do Sul/AC. Embora tenha motivado a chegada da FUNAI no Vale do Javari e justificado as tentativas de atração, a estrada não se aproximou dos territórios do povo Korubo. Foram construídos apenas alguns poucos quilómetros a partir de Benjamim Constant/AM.

É interessante observar que enquanto a grande maioria dos grupos e povos indígenas isolados da região se escondiam e camuflavam sua presença na medida em que se intensificava a penetração não indígena na região, o povo Korubo, mesmo nos anos mais violentos, aparecia periodicamente nas margens dos rios. Esses aparecimentos são registrados, pelo menos, desde a década de 1970. Embora os Korubo continuassem surgindo nas margens dos rios, a frequência desses aparecimentos diminuiu nas décadas seguintes, na medida em que se avolumava a exploração ilegal madeireira em seus territórios e o consequente aumento de massacres e conflitos. Essa penetração devastadora sobre territórios indígenas provocou cisões internas e forçosos processos migratórios relatados pelos próprios indígenas.

A proteção dos Korubo isolados se efetivou como uma ação estatal a partir da regularização fundiária da Terra Indígena Vale do Javari, em especial por meio da homologação pela Presidência da República e da demarcação física dessa terra indígena, no início dos anos 2000. Ao longo dos anos posteriores de apaziguamento e pacificação - com a extrusão de invasores - da região, os Korubo voltaram a aparecer nas margens dos rios da região, notadamente a partir 2005. A histórica prática dos Korubo isolados de se expor nas margens dos rios não significava, necessariamente, que haviam optado pelo contato, pelo menos não da forma que o Estado o entende.

A experiência em campo trouxe o entendimento de que os Korubo isolados adotavam uma estratégia de isolamento pautada por um significativo controle das relações. Comunicavam seu interesse na troca e na obtenção de objetos ("relação") e decidiam a época - em geral durante a estiagem -; o local - pontos determinados na margem dos rios-; e, ainda, a frequência e a intensidade dessas "relações". Eram os Korubo que pautavam a formatação dessas interações, inviabilizando a prática estatal de "atração" para estabelecer, à sua maneira, o rechaço a práticas e formas que não os interessavam naquele momento.

A partir de relatos dos Korubo atualmente em contato, constatou-se que apenas uma parcela do grupo se arriscava efetivamente nas margens dos rios. Demonstraram-se, portanto, diferenças dentro do próprio grupo no que diz

${ }^{18} 1987$ foi ano que se registrou o maior número de conflitos, conforme levantamento realizado no arquivo do antigo Departamento de Índios Isolados, da Funai, em 1997. (Funai. Cronologia de conflitos no Vale do Javari, 1997) 
respeito às estratégias de "relação" com agentes externos. Essas diferenças internas, de estratégias de "isolamento" pesaram, também, nos processos migratórios e de contatos ocorridos posteriormente.

\section{As diferentes expressões de autonomia dos povos isolados: o caso do povo Piripkura no Brasil}

O povo Piripkura constitui-se, atualmente, de três pessoas. São dois homens em situação de isolamento numa região no noroeste do estado do Mato Grosso, e uma mulher, Rita Piripkura, atualmente casada com um indígena Karipuna. A história deles ainda é bastante desconhecida, mas sabe-se que massacres desencadeados por não-indígenas contribuiu determinantemente para tal drástica redução demográfica. Existe, ainda, a possibilidade de parte dessa coletividade ter se refugiado em outras regiões vizinhas, permanecendo em isolamento. No entanto, essa é ainda uma conjectura ainda não confirmada pela Funai. Os Piripkura falam uma língua Tupi-Kawahiva, os dois homens conhecidos em situação de isolamento vivem numa área interditada pela Funai, no noroeste matogrossense.

Os dois indígenas Piripkura tiverem seu primeiro contato oficial com agentes da Funai em 1989. Outros contatos ocorreram nos anos subsequentes, de maneira intermitentemente. Em todas as situações de contato os dois Piripkura sempre optaram em voltar à floresta, em nenhum momento demonstraram interesse em sustentar tal relação de proximidade. A partir de meados da década de 1990, em virtude das limitações orçamentárias e de recursos humanos, a Funai se ausentou da região e direcionou as ações da unidade descentralizada que havia ali (Frente de Contato Madeirinha) para outras regiões do norte matogrossense.

Anos depois, em 2007, a Funai voltou à região com o intuito de localizar novamente os Piripkura. A expedição foi realizada pelo sertanista Jair Candor, que participou dos contatos anteriores, reconhecido pelos Piripkura como pessoa de confiança. A equipe localizou os indígenas, ocorrendo assim um novo contato físico. Esse contato motivou uma interdição territorial e a construção de uma Base de vigilância para o resguardo da vida dos indígenas. A equipe constatou que a área estava extremamente invadida por madeireiros e grileiros e que mesmo assim os Piripkura permaneciam vivos, graças às suas estratégias próprias.

Desde então, contatos da Funai com os Piripkura ocorrem periodicamente a cada um ou dois anos. Em todos os contatos os Piripkura voltam à situação de isolamento por vontade própria. No último contato, ocorrido em 2016, os Piripkura procuravam por fogo pois, até onde se sabe, os dois Piripkura não o produzem. O tição (fogo que eles carregam por anos) havia apagado com a intensa chuva de verão daquele ano. Os Piripkura foram até a Base de vigilância da Funai, encontraram a equipe da Funai e pediram que o acendesse novamente. 
Com o tição novamente aceso em mãos, rapidamente desapareceram na floresta. Até o momento (junho de 2017) não foram mais vistos.

Nesse caso, mesmo cientes do potencial que uma relação contínua poderia prover, os Piripkura sempre optam por manter distância e decidem o lugar e quando estabelecer relações mais próximas. A equipe local da Funai respeita essa decisão e não promove quaisquer relações forçadas, é o ato da espera em respeito às suas decisões.

\section{As diferentes expressões de autonomia dos povos isolados: 0 caso do povo Machiguega-Nanti no Peru}

Os Machiguenga-Nanti são um povo indígena da família linguistica Arawak (Beier, 2008). Habitam a Reserva Territorial Kugapakori, Nahua, Nanti e outros (RTKNO), no departamento de Cusco, no Peru. A RTKNO tem parte de sua área sobreposta a um bloco de concessão para a exploração de hidrocarbonetos (bloco 88) (Barcklay 2014). Os Machiguenga-Nanti atravessaram dois momentos principais de contato: o primeiro ocorreu entre 1974 e 1977, com missionários Dominicanos, nas cabeceiras do rio Tímpia; e o segundo em razão de migrações do rio Tímpia para o rio Camisea, a partir de 1987 e até os dias atuais (Beier 2008).

Nesse processo, calcula-se que morreram entre $30 \%$ a $50 \%$ da população Machiguenga-Nanti por surtos epidêmicos (Beier 2008). No rio Camisea, a população Machiguenga-Nanti é de pouco mais que 400 pessoas e não há informações atualizadas sobre o tamanho populacional dos MachiguengaNanti isolados (Barcklay 2014). Entretanto, há estimativas que apontam, em 2008, uma população aproximada de 100 pessoas (Beier 2008). Interessante observar que a divisão dos Machiguenga-Nanti ocorre em função das diferentes estratégias de relações adotadas pelos distintos grupos - do rio Camisea e do rio Tímpia.

Enquanto os Machiguenga-Nanti do rio Camisea optaram por se relacionar mais intensamente com o entorno - tendo como um dos intuitos a obtenção de ferramentas - os do rio Tímpia decidiram permanecer com pouca ou nenhuma interação.

Los Nantis del Camisea opinam que los del Tímpia han elegido voluntariamente vivir allí y que muchos de ellos están evitando el tipo de vida social - y especialmente el contacto con los forasteros - que se experimenta em la Cuenca del Camisea. Los Nantis del Camisea afirman que los del Timpía tienen conocimiento de la existencia del mundo no Nanti pero no lês interessa contactarse com él. Los Nantis del Camisea muestran respeto por la autonomia y las decisiones de las personas del Timpía, pues para ellos la situación es muy clara: 
aquellos interesados em el mundo no Nanti se trasladan a vivir al Camisea; aquellos que no tienen interés, simplemente no lo hacen. (Beier 2008)

Observa-se também no caso dos Machiguenga-Nanti do rio Tímpia a estratégia do controle das relações por meio do chamado isolamento. Corroborando com nossos argumentos, a mesma autora (Beier 2008) afirma, ainda, que:

La diferencia de actitud entre los Nantis del Camisea, quienes han optado por mantener un nível de contacto com gente no Nanti, y aquellos del Timpía, que han optado por evitarlo, refuerza el argumento de que uma población que há logrado continuar viviendo en aislamento hasta el presente lo hace deliberadamente y com plena voluntad.

Constata-se que, ao adotarem a estratégia do maior controle das relações - pelo isolamento -, esses povos ou grupos indígenas visam diminuir sua vulnerabilidade, especialmente no que diz respeito às vulnerabilidades que são consequências de relações não controladas (pelos indígenas) com o entorno. Por outro lado, para que essa estratégia autônoma se efetive, são necessárias uma série de condições, como a manutenção ambiental de seus territórios. Assim, não são os grupos ou povos isolados que se vulnerabilizam ao decidirem pela estratégia de isolamento. O momento de descontrole sobre a gestão dessas relações - contatos forçados e degradação de seus territórios - é justamente o que os expõe ao mais alto grau de vulnerabilidade.

Comparativamente, no caso dos Korubo no Brasil, fica evidente o elo entre o aumento da vulnerabilidade com a perda da autonomia ou do controle indígena das relações. Ou seja, a invasão de seus territórios por madeireiros, seringueiros e equipes de prospecção - enquanto, simultaneamente, a Funai desencadeava processos de contato alheios às suas estratégias de vida - acarretou situações de extrema vulnerabilidade social e física. Essa conjuntura de descontrole resultou no rearranjo forçado dos seus processos territoriais (diáspora), bem como em conflitos e mortes.

Outro elemento importante é a constatação de que há grupos que decidem pela estratégia de isolamento fundamentados por experiências traumáticas anteriores, daí os questionamentos recorrentes sobre o uso do termo isolamento voluntário. É necessário considerar que se por um lado as experiências traumáticas podem fundamentar as estratégias de controle de relações (isolamento), por outro, as mesmas experiências, podem contribuir na decisão de se submeter ao contato. Isso vem ocorrendo, por exemplo, nos casos em que grupos isolados optam pelo contato após a ocorrência de conflitos, doenças, entre outras experiências negativas.

No que tange ao desenvolvimento e execução das políticas públicas, independentemente da tradução, comparação ou equivocação (Viveiros de Castro 
2004) acerca do fundamento das estratégias adotadas pelos grupos isolados, ou por quaisquer outros grupos indígenas, o que deve pesar é a consideração da decisão indígena em si, especialmente no que diz respeito à relação com seu território, com o Estado e/ou com a sociedade externa. É preciso que a compreensão, ainda que limitada, do isolamento nos ajude a superar, enquanto sociedade e instituições estatais, práticas de dominação e colonização. Assim, sobre as equipes de atração (os agentes do contato) da Funai:

No cotidiano de sua atuação, a maior parte dos agentes de contato não toma consciência de estar promovendo relações de dominação. Os índios, quanto a eles, tem plena consciência destas relações e se prestam, através de estratégias diversas, ao jogo da submissão. (Gallois 1992)

\section{Releitura do direito de consulta:}

A estratégia de controle de relações de povos e grupos indígenas "isolados" deve, portanto, ser considerada para fazer avançar o direito de consulta da Convenção 169 da OIT, constituindo uma necessária releitura social e jurídica, tanto em relação aos isolados como em relação aos demais povos indígenas. Fundamentalmente, a garantia de direitos fundamentais e do respeito às formas de organização e aos modos de vida de povos indígenas exigem que processos de consultas - que é a consideração pelo Estado da expressão indígena sobre o que lhe afeta seus modos de vidas - sejam plurais, não sejam nem impostos e nem ignorados pelos governos.

Portanto, o estabelecimento de protocolos específicos para a administração de processos de consulta, por exemplo relacionados a estudos de impacto ambiental de grandes empreendimentos, surge como instrumento fundamental para a garantia de direitos de acordo com os standards e as normativas internacionais de direitos humanos. Entendemos que tais protocolos devem considerar a metodologia utilizada pela Funai, cujas informações levantadas devem ser revisadas e referendadas por representantes do movimento indígena, pelo Ministério Público Federal e representantes da sociedade civil com conhecimento sobre a questão.

A não imposição de contato pelo Estado - tal como já está estabelecida em consolidada política nacional - constitui a primeira ação para o respeito à autonomia de grupos ou povos isolados. Por razões de coerência, uma ação estatal diferenciada para a proteção dos territórios e dos recursos naturais imprescindíveis para a vida desses povos deve acompanhar o princípio do nãocontato. Consequentemente, é a expressão de vontades dos povos isolados que deve orientar as decisões estatais que os afetam.

Considerando que as estratégias de controle de relações (ou de isolamento) desenvolvidas pelos grupos isolados ocorrem a partir de decisões fundamentadas, por lógicas ou motivações que não necessariamente compreendemos, mas que visam diminuir seu grau de vulnerabilidade e manter suas formas próprias de 
vida, podemos inferir que povos isolados expressam sua autonomia pela opção do isolamento. Ao fazerem isso, revelam ao Estado seu não consentimento, pelo menos, quanto ao: (a) desencadeamento de processos forçados de contato; e (b) quanto à ações que acarretam na degradação ou destruição ambiental de seus territórios.

De fato, as relações que os isolados estabelecem comunicam-se na forma de vestígios que deixam propositalmente, como tapagens ou armadilhas em caminhos, como que avisando: "daqui não queremos que você passe". Igualmente, a própria tentativa de invisibilizar sua presença para nós pode ser consequência de uma relação que eles conhecem e portanto adotam cuidados específicos.

Em suma, exceto os caso em que os próprios índios provocam relações mais próximas, qualquer intervenção que desencadearmos de contato físico com esses povos é envolto de descontrole e de imprevisibilidade. Isso porque, não compreendemos o suficiente essa relação e, ao mesmo tempo, sabemos estar violando suas decisões e expressões de autonomia. É preciso afastar de vez o pensamento colonialista e tutelar, visto que não temos a capacidade de decidir o que é melhor para eles, mais do que eles próprios. Nesse sentido, aplicar o direito de consulta e consentimento é encontrar formas de reconhecer e respeitar os processos de vida dos povos indígenas, inclusive os isolados.

\section{Bibliografia}

Acnudh. 2012. Directrices de protección para los pueblos indígenas en aislamiento y en contacto inicial de la region amazónica, em gran Chaco y la región oriental de Paraguay, ONU.

Amorim, Fabrício. 2014. Relatório sobre contato estabelecido com um grupo indígena isolado da etnia Korubo, no rio Itaquai (TI Vale do Javari). Funai/CGIIRC.

Amorim, Fabrício. Povos isolados: novos desafios da ação indigenista oficial. In: Instituto Socioambiental (Org). Povos Indígenas no Brasil 2011/2016, p. 62-66.

Anaya, S. James. 2009. Informe del Relator Especial sobre la situación de los derechos humanos y las libertades fundamentales de los indígenas, James Anaya. 15 de julio de 2009. A/HRC/12/34

Anaya, S. James. 1996. Indigenous Peoples in International Law. Oxford University Press.

Barclay, Frederica \& Hierro, Pedro García. 2014. La Batalla por "los Nanti”: Interes y discursos superpuestos a favor de la extinción de la Reserva Territorial Kugapakori Nahua Nanti y otros. Informe IWGIA 17. IWGIA.

Beier, Christine. 2008. El caso de los Nantis del sureste del Perú. In: El derecho a la salud de los pueblos indigenas en aislamiento y en contacto inicial. IWGIA/IPES/ Fundación Biodiversidad.

CIDH. 2013. Pueblos indígenas en aislamiento voluntario y contacto inicial en las Americas: recomendaciones para el pleno respeto a sus derechos humanos. IWGIA/ OEA. 
Coutinho JR., Walter - FUNAI. 1998. Relatório Circunstanciado de Identificação e Delimitação da Terra Indígena Vale do Javari. Funai.

Gallois, Dominique Tilkin. De arredio a isolado: perspectivas de autonomia para os povos indígenas recém-contactados. In: Índios no Brasil, 1992. P.121-134

Gow, Peter. "Me deixa em paz!” 2011. Um relato etnográfico preliminary sobre o isolamento voluntário dos Mashco. University of St Andrews.

Huertas, Beatriz. 2010. Despojo territorial, conflict social y exterminio: pueblos indigenas en situación de aislamiento, contacto esporádico y contacto inicial de la Amazonia peruana. Informe IWGIA 9. IWGIA.

Labiak, Araci Maria \& Neves, Lino João O. 1984. A Petrobrás e os arredios do Itacoaí e Jandiatuba: “Apocalipse Now”, em silêncio. In: CEDI. Povos Indígenas no Brasil.

MINISTERIO DE LA SALUD. 2003. Pueblos en situación de extrema vulnerabilidad: el caso de los Nanti de la Reserva territorial Kugapakori Nahua - Rio Camisea, Cusco. Oficina General de Epidemiologia.

Nascimento, Hilton Silva do. Los pueblos indígenas aislados de la frontera Brasil-Perú: nuevas amenazas y desafíos para la garantía de sus derechos. Mundo Amazónico 2, 2011. P. 179-198.

Octavio, Conrado R. \& Azanha, Gilberto. 2009. Isolados - algumas questões para reflexão. CTI.

Oliveira, Sanderson Castro Soares. Preliminares sobre a fonologia da língua falada pelo primeiro grupo de índios Korubo recém contatados. UNB, 2009.

Rojas Garzón, Biviany; Yamada, Erika; Oliveira, Rodrigo. 2016. Direito à consulta e consentimento de povos indígenas, quilombolas e comunidades tradicionais. RCA e DPLF.

Silva, Cristhian. 2006. O silêncio das trocas e a domesticação dos brancos: Formas de contato Ava-Canoiero no Alto Rio Tocantins - Brasil. Archivos, v. IV, p. 91-136, 2006.

Vaz, Antenor. 2011. Isolados no Brasil: Política de Estado: da tutela para a política de direitos - uma questão resolvida? Informe IWGIA 10. Iwgia.

Viveiros de Castro, Eduardo. 2004. Perspectival Anthropology and the Method of Controlled Equivocation. Tipiti: Journal of the Society for the Anthropology of Lowland South America: Vol.2:Iss.1, article 1.

Yamada, Erika - FUNAI. 2013. Nota Técnica n.10 Direito de Consulta Previsto na Convenção 169 da OIT - subsídios para casos UHE Tapajós, PL1610 (mineração em terras indígenas) e outros. CGPC/DPDS/Funai.

Yamada, Erika \& Oliveira, Lucia Alberta Andrade - FUNAI. 2013.A Convenção da OIT e o Direito de Consulta Livre Prévia e Informada. Funai/GIZ.

http://www.academia.edu/21469123/Trocas silenciosas e a domestica $\% \mathrm{C} 3 \% \mathrm{~A} 7 \% \mathrm{C} 3 \% \mathrm{~A} 3 \mathrm{O}$ dos brancos Formas de contato Av $\% \mathrm{C} 3 \% \mathrm{~A} 1$-Canoeiro no Alto Rio Tocantins Brasil

Recebido em setembro de 2016

Aceito em outubro de 2016 